\title{
EFFECT OF CAESALPINIA BONDUCELLA L. ON ULCER AND GASTRIC SECRETIONS IN PYLORUS LIGATED RAT MODEL
}

\author{
*Javed Akhtar Ansari ${ }^{1}$, Shafique Ahmad ${ }^{2}$, Mohd Jameel ${ }^{3}$ \\ ${ }^{1}$ MESCO College of Pharmacy, 13-5-741, MEC, Mustaeedpura, Karwan Road, Hyderabad-500 006, India \\ ${ }^{2}$ Faculty of Pharmacy, Dept of Pharmacolgy, Jamia Hamdard, New Delhi-110062, India \\ ${ }^{3}$ Faculty of Pharmacy,Dept of Pharmacognosy Jamia Hamdard, New Delhi-110062, India \\ *Corresponding author's Email ID: javed.ansari47@gmail.com
}

Received 04 August 2012; Review Completed 13 Sep 2012; Accepted 13 Sep 2012, Available online 15 Sep 2012

\begin{abstract}
In the present study, aqueous extract Caesalpinia bonducella (CBD; Karanjwa) was evaluated for antiulcer and antisecretory potential in pylorus ligated rat model. CBD is an important medicinal plant having multiple therapeutic properties viz. topical anti-inflammatory, antipyretic, antidiuretic, anthelmintic and antibacterial, anticonvulsant, anti-anaphylactic and antidiarrhea, antiviral, antiasthmatic, antiamoebic and antiestrogenic effects. Phytochemical screening of the aqueous extracts showed the presence of alkaloids, saponins, flavonoids, triterpenes, tannins and steroids. Ulcer was induced by pylorus ligation in Wistar rats. The aqueous extract from the leaves of CBD were tested orally at the doses of 500, 750 and $1000 \mathrm{mg} / \mathrm{kg}$. The aqueous extract of $\mathrm{CBD}(500,750$ and $1000 \mathrm{mg} / \mathrm{kg})$ produced significant antiulcer and antisecretory effects, respectively. Observations of the present study could justify, at least partially, the inclusion of this plant in the management of gastric disorders in traditional medicine.

Keywords: Pylorus ligation, total acidity, free acidity.
\end{abstract}

\section{INTRODUCTION}

Caesalpinia bonducella (CBD; Karanjwa) is an important medicinal plant extensively distributed throughout the coastal region of India, Burma, Sri Lanka, and in other tropical and subtropical regions of the world ${ }^{1-3}$. It is an irregular thorny shrub with large bipinnate leaves. Its flowers are yellow and fruits are inflated pods having 1-2 seeds ${ }^{4}$. The leaves of CBD are conventionally used for the treatment of inflammation and toothache. The topical antiinflammatory action of CBD leaves has been reported. It has also been found to posses multiple therapeutic properties viz. antipyretic, antidiuretic, anthelmintic and antibacterial, anticonvulsant, anti-anaphylactic and antidiarrhea, antiviral, antiasthmatic, antiamoebic and antiestrogenic ${ }^{5}$.

Peptic ulcer is a lesion of gastric or duodenal mucosa happening at a site where the mucosal epithelium is exposed to aggressive factors. Despite the vast amount of research on ulcer, the cause of chronic peptic ulceration is still not clear. Though in most of the cases the aetiology of the ulcers is unknown, it is generally accepted that they result from an imbalance between aggressive factors and the maintenance of mucosal integrity through endogenous defence mechanisms ${ }^{6}$. Drug management of peptic ulcers is targeted at either counteracting these aggressive factors or stimulating the mucosal defence ${ }^{7}$. Despite the progress in conventional chemistry and pharmacology in producing effective drugs, the plant kingdom might provide a useful source of new antiulcer compounds for development as pharmaceutical entities or, alternatively, as simple dietary adjuncts to existing therapies ${ }^{8}$.

\section{MATERIAL AND METHODS}

\section{Plant}

Fresh leaves of CBD were collected from Chidambaram, Cuddalore, Tamil Nadu, India. The plant was identified and authenticated by Prof. Dr. R. Selvaraj, Chief Botanist, Department of Botany, Annamalai University, Annamalai Nagar Chidambaram, Cuddalore, Tamil Nadu, India.

\section{Drugs and chemicals}

Omeprazole was obtained from Zydus Research Centre, India. All other chemicals used in this study were obtained commercially and were of analytical grade.

\section{Aqueous extract of Caesalpinia bonducella leaves}

The dried plant material (500 g) CBD leaves were extracted three times by refluxing with distilled water for 8 hrs and the filtered extract was evaporated on a water bath to get a viscous aqueous extract.

\section{Phytochemical screening}

The aqueous extract of CBD was subjected to phytochemical screening 9,10 .

\begin{abstract}
Animals
The study was conducted after obtaining institutional ethical committee (MESCO College of Pharmacy, Mustaidpura, Hyderabad, Andhra Pradesh, India, No.: 1185/a/08/CPCSEA; Committee for Control and Supervision on Experiments on Animals). Female Wistar rats (100-150 g; 4-6 weeks old) were maintained under
\end{abstract}


controlled conditions of light $(12 \mathrm{~h} / 12 \mathrm{~h})$, temperature $\left(26 \pm 2{ }^{\circ} \mathrm{C}\right)$ and relative humidity $(44-56 \%)$ for 1 week before and during the experiments. The animals had access to standard laboratory feed (Gold Mohur, Hindustan Lever Ltd., Mumbai, India) and water ad libitum. For experimental purposes, animals were kept fasting overnight but were allowed free access to water.

\section{Experimental procedure}

\section{Determination of total acidity}

An aliquot of $1 \mathrm{ml}$ gastric juice was taken into a $50 \mathrm{ml}$ conical flask and two drops of phenolphthalein indicator was added to it and titrated with $0.01 \mathrm{~N} \mathrm{NaOH}$ until a permanent pink colour was observed. The volume of $0.01 \mathrm{~N} \mathrm{NaOH}$ consumed was noted. The total acidity is expressed as meq/l by the following formula: $n \times 0.01 \times$ $36.45 \times 1000$ where $n$ is volume of $\mathrm{NaOH}$ consumed, 36.45 is molecular weight of $\mathrm{NaOH}, 0.01$ is normality of $\mathrm{NaOH}, 1000$ is the factor (to be represented in litre).

\section{Determination of free acidity}

Instead of phenolphthalein indicator, the Topfer's reagent was used. Aliquot of gastric juice was titrated with $0.01 \mathrm{~N}$ $\mathrm{NaOH}$ until canary yellow colour was observed. The volume of $0.01 \mathrm{~N} \mathrm{NaOH}$ consumed was noted. The free acidity was calculated by the same formula for the determination of total acidity (Trease and Evans, 1992) ${ }^{9}$.

\section{Ulcer score}

The gastric mucosa was examined for ulcers by magnifying lens and the ulcer scored according to its severity in comparison with that of standard. Ulcer score was recorded as 0, normal stomach / no ulcer; 0.5, red coloration 1, isolated haemorrhagic spot; 1.5, hemaorrhagic streaks 2 , Ulcer $>3 \mathrm{~mm}$ but $<5 \mathrm{~mm}$; 3 , ulcer $>5 \mathrm{~mm}^{11}$. the formula.

The percentage protection was calculated using

Percentage protection $=100-\left(\frac{u t}{u c} \times 100\right)$

Where, $u t=$ Ulcer index of treated group, $u c=$ Ulcer index of control group.
Mean ulcer score for each animal is expressed as ulcer index.

\section{Pylorus ligated-induced ulcers}

The animals were divided into 5 groups of 6 animals each. Groups 1 served as negative controls and received suspension of $1 \%$ carboxymethyl cellulose in distilled water $(10 \mathrm{ml} / \mathrm{kg})$. Groups 2 served as positive controls and received Omeprazole $(8 \mathrm{mg} / \mathrm{kg})$ as standard. Groups 3-5 received the aqueous extracts at the doses of 500, 750 and $1000 \mathrm{mg} / \mathrm{kg}$. All treatments were administered orally at corresponding volume of $1 \mathrm{ml} / 100 \mathrm{~g}$ body weight.

Pylorus ligation was made $1 \mathrm{~h}$ after treatment. Six hours after the ligation, the animals were sacrificed and the stomach removed. The gastric contents were collected, centrifuged and the supernatant measured. The ulcer formed in the gastric mucosa were measured and scored as described by ${ }^{12}$. The ulcer index, the percentage ulcerated surface and the percentage of inhibition were estimated as described above. One millilitre of the total centrifuged gastric contents from each pylorus-ligated rat was analysed for hydrogen ion concentration by titrating against a $0.01 \mathrm{~N}$ solution of $\mathrm{NaOH}$ using a pH meter (Santex TS-2). The experiment was done in triplicate.

\section{Statistical analysis}

Statistical analysis was performed using ANOVA followed by Tukey's test and significance of difference between treatments was accepted at $p<0.05$. Data are expressed as mean \pm standard error of the mean.

\section{RESULTS AND DISCUSSION}

On preliminary phytochemical study the aqueous extract of CBD showed the presence of alkaloids, saponins, flavonoids, triterpenes, tannins and steroids. Flavonoids have been reported to have a significant anti-ulcer activity, in various experimental models of gastric and duodenal ulceration ${ }^{13}$. Oral treatment with the flavonoid extract exposed good level of gastric protection ${ }^{14}$.

Oral administration of test extracts of CBD in different doses of $500,750 \& 1000 \mathrm{mg} / \mathrm{kg}$ showed significant graded and dose dependent decrease in ulcer index, respectively. The extracts also significantly reduced the gastric volume, total and free acidity, and increased the $\mathrm{pH}$ of the gastric fluid (Table $1 \& 2$ ).

Table 1: Effect of Caesalpinia bonducella L. extract on acid secretary parameters in pylorus ligation-induced gastric secretion model

\begin{tabular}{|c|c|c|c|c|}
\hline Treatment & $\begin{array}{l}\text { Volume of Gastric } \\
\text { Juice }(\mathrm{ml})\end{array}$ & $\begin{array}{l}\text { Free Acidity } \\
(\mathrm{m} \text { eq/I } 100 \mathrm{gm})\end{array}$ & $\begin{array}{l}\text { Total Acidity } \\
(\mathrm{m} \text { eq/I } 100 \mathrm{gm})\end{array}$ & $\mathrm{p}^{\mathrm{H}}$ \\
\hline Control $(1 \%$ w/v CMC, $10 \mathrm{ml} / \mathrm{kg})$ & $3.5 \pm 3.27$ & $34.45 \pm 5.32$ & $75.70 \pm 13.04$ & $2.5 \pm 0.34$ \\
\hline Omeprazole $(8 \mathrm{mg} / \mathrm{kg})$ & $1.425 \pm 0.17 * * *$ & $3.51 \pm 0.45^{* * *}$ & $8.86 \pm 0.77 * *$ & $5.89 \pm 0.45^{* * *}$ \\
\hline $\mathrm{CBD}(500 \mathrm{mg} / \mathrm{kg})$ & $3.12 \pm 0.30$ & $23.32 \pm 2.0$ & $44.40 \pm 5.50$ & $4.00 \pm 0.45$ \\
\hline $\mathrm{CBD}(750 \mathrm{mg} / \mathrm{kg})$ & $2.4 \pm 0.25$ & $17.42 \pm 2.90$ & $38.15 \pm 2.50$ & $3.89 \pm 0.22$ \\
\hline CBD $(1000 \mathrm{mg} / \mathrm{kg})$ & $1.98 \pm 0.17$ & $13.54 \pm 1.40$ & $23.22 \pm 2.00$ & $4.86 \pm 0.24$ \\
\hline
\end{tabular}

All values represents mean $\pm S E M, n=6$ in each group.

$* * P<0.05, * * P<0.01$ and $* * * P<0.001$ when compared with control group (ANOVA, followed by Tukey's multiple range test). 
Table 2: Effect of Caesalpinia bonducella $\mathrm{L}$. extract on pylorus-ligated ulcer model in rats

\begin{tabular}{ll}
\hline Treatment & Mean ulcer index \\
\hline Control $(10 \mathrm{ml} / \mathrm{kg})$ & $6.00 \pm 0.89$ \\
Omeperazole $(8 \mathrm{mg} / \mathrm{kg})$ & $0.63 \pm 0.25^{* * *}$ \\
CBD $(500 \mathrm{mg} / \mathrm{kg})$ & $3.63 \pm 0.94$ \\
CBD $(750 \mathrm{mg} / \mathrm{kg})$ & $2.85 \pm 0.76^{* *}$ \\
CBD $(1000 \mathrm{mg} / \mathrm{kg})$ & $2.55 \pm 0.86$ \\
\hline
\end{tabular}

\footnotetext{
All values represents mean $\pm S E M, n=6$ in each group. ** $P<0.01$ and $* * * P<0.001$ when compared with control group (ANOVA, followed by Tukey's multiple range test).
}

Ulcers caused by pyloric ligation are due to amplified accumulation of gastric acid and pepsin, leading to the autodigesion of gastric mucosa and break down of the gastric mucosal barrier ${ }^{15,16}$. The present study shows that CBD treated groups showed a significant $(P<$ 0.001 ) increase in gastric juice $\mathrm{pH}$, reduced gastric volume, free acidity and total acidity when compared to control. This effect was similar to omeprazole treated group. CBD diminished the ulcer index more effectively in a dose dependent manner. These results revealed that

\section{REFERENCES}

1. Anonymous. Wealth of India Delhi: CSIR Publications. 1956, pp 6-8.

2. Gamble JS. Flora of presidency of Madras Calcutta: Botanical Survey of India. 1967, pp. 278-279.

3. Kapoor LD. Handbook of ayurvedic medicinal plants. Boca Raton: CRC Press LLC. First Indian Reprint, Herbal Reference Library, Replika Press Pvt. Ltd., India. 2008, pp 88.

4. Prajapati ND, Purohit SS, Sharma AK, Kumar T. A handbook of medicinal plants a complete source book, reprint. Agrobios, Jodhpur, India: Hindustan Printing Press. 2006, p. 100.

5. Wadkar GH, Kane SR, Matapati SS, Hogade MG. In-vitro anthelmintic activity of Caesalpinia bonducella (Linn). Flem. leaves. Journal of Pharmacy Research 2010, 3(5), 926-927.

6. Govindarajan R, Vijayakumar M, Singh M, Rao ChV, Shirwaikar A, Rawat AKS, Pushpangadan P. Antiulcer and antimicrobial activity of Anogeissus latifolia. Journal of Ethnopharmacology, 2006, 106, 57-61.

7. Arrieta J, Benitez J, Flores E, Castillo C, Navarrete A. Purification of gastroprotective triterpenoids from the stem bark of Amphipterygium adstringens; role of prostaglandins, sulfhydryls, nitric oxide and capsaicin-sensitive neurons. Planta Medica, 2003, 69(10), 905.

8. Borrelli F, Izzo AA. The plant kingdom as a source of antiulcer remedies. Phytotherapy Research, 2000, 14 (8), 581.

9. Trease GE and WC Evans.. Text Book of Pharmacognosy, $15^{\text {th }}$ edition. Saunders publishers, London, (2002) pp. 42-44,221229,246-249,304-306,331-332,391-393,414-415.

10. Khandelwal KR. Practical Pharmacognosy, 11th ed. Nirali Prakashan, Pune. 2004, pp. 149-156.

11. Kulkarni SK. Hand Book of Experimental Pharmacology. $3^{\text {rd }}$ ed, new Delhi: Vallabh Prakash, pp. 2000, 148-50.

12. Shay H, Komarov SA, Fels SS, Meranze D, Gruenstein M, Siplet H. A simple method for the uniform production of gastric ulceration. Gastroenterology, 1945, 5, 43-61.

13. Parmar NS, Desai JK. A review of the current methodology of the evaulation of gastric and duodenal anti ulcer agents. Indian Journal of Pharmacology, 1993, 25, 120-35. the antiulcer activity of CBD might be due to its antisecretory activity.

It can be conceived that aqueous extract of CBD, exerts its anti-ulcer activity with the flavonoids. Results suggest that CBD extract could be useful component of preventing ulcer formation as well as antisecretory activity. Thus our study recognized a significant antiulcer, antisecretory effect of aqueous extract of CBD leaf.

\section{CONCLUSION}

The present results clearly indicate that oral administration of aqueous extract of CBD flower at different doses of 500, 750 and $1000 \mathrm{mg} / \mathrm{kg}$ in pylorus ligated model produce a significant graded and dose dependent antiulcer as well as anti secretary activity when compared to control (vehicle) group using omeprazole $8 \mathrm{mg} / \mathrm{kg}$ as standard. Observations of the present study could justify, at least partially, the inclusion of this plant in the management of gastric disorders in traditional medicine. However further studies are required to establish its exact mode of action, isolation and characterization of constituents responsible for activity.

14. Alarcon DLLC, Martin MJ, Lacasa C, Motilva V. Antiulcerogenic activity of flavonoids and gastric protection. Journal of Ethnopharmacology, 1994, 42, 161-18.

15. Goel RK, Bhattacharya SK. Gastroduodenal mucosal defense and protective agents. Indian Journal of Experimental Biology, 1991, 29, 701-714.

16. Sairam K, Rao ChV, Babu DM, Agrawal VK, Goel RK. Antiulcerogenic activity of methanolic extract of Emblica officinalis. Journal of Ethnopharmacology, 2002, 82 (1), 1-9. 